\title{
Biosurfactant production by Bacillus subtilis using corn steep liquor as culture medium
}

\author{
Eduardo J. Gudiña, Elisabete C. Fernandes, Ana I. Rodrigues, José A. Teixeira and Lígia R. Rodrigues*
}

CEB - Centre of Biological Engineering, University of Minho, Braga, Portugal

\section{Edited by:}

Pattanathu K. S. M. Rahman, Teesside

University, UK

\section{Reviewed by:}

Mei-Fang Chien, Tohoku University, Japan

Deisi Altmajer Vaz, University of

Granada, Spain

*Correspondence:

Lígia R. Rodrigues, CEB - Centre of Biological Engineering, University of Minho, 4710-057 Braga, Portugal

e-mail: Irmr@deb.uminho.pt
In this work, biosurfactant production by Bacillus subtilis \#573 was evaluated using corn steep liquor (CSL) as culture medium. The best results were obtained in a culture medium consisting of $10 \%(\mathrm{v} / \mathrm{v})$ of CSL, with a biosurfactant production of about $1.3 \mathrm{~g} / \mathrm{l}$. To the best of our knowledge, this is the first report describing biosurfactant production by $B$. subtilis using CSL as culture medium. Subsequently, the effect of different metals (iron, manganese, and magnesium) on biosurfactant production was evaluated using the medium CSL $10 \%$. It was found that for all the metals tested, the biosurfactant production was increased (up to $4.1,4.4$, and $3.5 \mathrm{~g} / \mathrm{l}$ for iron, manganese, and magnesium, respectively). When the culture medium was supplemented with the optimum concentration of the three metals simultaneously, the biosurfactant production was increased up to $4.8 \mathrm{~g} / \mathrm{l}$. Furthermore, the biosurfactant exhibited a good performance in oil recovery assays when compared with chemical surfactants, which suggests its possible application in microbial enhanced oil recovery or bioremediation.

Keywords: Bacillus subtilis, corn steep liquor, surfactin, bioremediation, microbial enhanced oil recovery

\section{INTRODUCTION}

Surfactants are an important class of chemical compounds included in many of the everyday products we use. They can be found in detergents, laundry formulations, household cleaning products, cosmetics, herbicides, or pesticides, and are also used in bioremediation, agriculture, food, pharmaceutical, textile, paper, or petroleum industries, among others (Geys et al., 2014; Rebello et al., 2014). Surfactants are amphiphilic molecules that, due to their structure, tend to accumulate at the interfaces between fluid phases with different polarities (e.g., oil-water or air-water), reducing surface and interfacial tensions (Gudiña etal., 2013). Most of the surfactants currently used are chemically synthesized from petrochemical resources and are only partially biodegradable, causing detrimental effects on the environment (Vaz et al., 2012; Rebello et al., 2014).

Nowadays, due to the increasing environmental awareness, the demand for surfactants obtained from bio-based resources is increasing. Biosurfactants, surface-active compounds synthesized by a variety of microorganisms, are attracting a pronounced interest owing to their potential advantages over their chemical counterparts, namely they exhibit a similar or better performance and have less impact on the environment than conventional surfactants, due to their lower toxicity and higher biodegradability. Furthermore, biosurfactants are usually effective at extreme environmental conditions and can be produced from renewable resources (Pereira et al., 2013; Gudiña et al., 2015). As a consequence, biosurfactants can replace some of the synthetic surfactants in many fields. However, the application of biosurfactants depends on whether they can be produced economically at large-scale. Presently, biosurfactants are not competitive with chemical surfactants from an economic point of view, since expensive substrates are required for their production and they present relatively low productivities, which hampers their widespread use and commercialization. As the culture medium can account for up to $30-50 \%$ of the overall production costs of biosurfactants, the replacement of expensive synthetic media by cheaper agro-industrial wastes and by-products can contribute to reduce their production costs and increase their competitiveness (Henkel et al., 2012; Al-Bahry et al., 2013; Gudiña et al., 2015).

Biosurfactants display a wide variety of chemical structures, including glycolipids, lipopeptides, phospholipids, fatty acids, or neutral lipids, among others (Gudiña et al., 2013; Geys et al., 2014). Bacillus species produce a broad spectrum of lipopeptide biosurfactants, which are cyclic molecules consisting of a fatty acid of variable length (hydrophobic moiety) linked to a short peptide chain (hydrophilic moiety) of seven or ten aminoacids. Among them, surfactin, a lipoheptapeptide produced by Bacillus subtilis strains, is one of the most effective biosurfactants known so far; it can reduce the surface tension (ST) of water up to $27 \mathrm{mN} / \mathrm{m}$, with critical micelle concentrations $(\mathrm{cmc})$ as low $0.01 \mathrm{~g} / \mathrm{l}$, and shows a high emulsifying activity; furthermore, it exhibits antimicrobial, antiviral, and antitumor activities (Gudiña et al., 2013). Consequently, surfactin can be potentially useful in numerous therapeutic, industrial, and environmental applications. In order to reduce the production costs, surfactin production by B. subtilis strains has been studied using different substrates, such as molasses (AbdelMawgoud et al., 2008; Joshi etal., 2008; Al-Bahry et al., 2013), potato peels (Das and Mukherjee, 2007), whey powder (CagriMehmetoglu etal., 2012), cashew apple juice (Oliveira et al., 2013) or cassava waste water (Nitschke and Pastore, 2006). Furthermore, the effect of different nutritional factors has been studied to improve surfactin production by $B$. subtilis strains. 
Among them, it has been reported that the addition of various metals (i.e., iron, magnesium, and manganese) to the culture medium contribute to increase its production, since those elements are co-factors of enzymes involved in the synthesis of surfactin (Thimon etal., 1992; Makkar and Cameotra, 2002; Wei et al., 2003).

In this work, biosurfactant production by a B. subtilis strain was evaluated using the agro-industrial by-product corn steep liquor (CSL) as a low-cost alternative substrate. Once established the optimum CSL concentration for biosurfactant production, the culture medium was optimized by supplementing it with different metals (iron, magnesium, and manganese) at different concentrations, first individually and then in different combinations. Finally, the applicability of the biosurfactant produced in oil recovery was evaluated.

\section{MATERIALS AND METHODS BACTERIAL STRAIN}

The biosurfactant-producing strain B. subtilis \#573 was isolated and identified in our laboratory in a previous work (Gudiña et al., 2012). The strain was stored at $-80^{\circ} \mathrm{C}$ in Luria-Bertani (LB) medium supplemented with $20 \%(\mathrm{v} / \mathrm{v})$ of glycerol. The composition of LB medium was $(\mathrm{g} / \mathrm{l})$ : $\mathrm{NaCl} 10.0$; tryptone 10.0; yeast extract 5.0; $\mathrm{pH}$ 7.0. Whenever required, frozen stocks were streaked on LB agar plates and incubated at $37^{\circ} \mathrm{C}$ for $24 \mathrm{~h}$. The agar plates were stored at $4^{\circ} \mathrm{C}$ no longer than 3 weeks.

\section{BIOSURFACTANT PRODUCTION BY B. subtilis \#573 USING CSL}

Corn steep liquor was kindly provided by COPAM [Companhia Portuguesa de Amidos, S. A. (Portugal)], and it was evaluated as a substrate for biosurfactant production by B. subtilis \#573. Total carbohydrates and protein concentrations in CSL were determined using the phenol-sulfuric and Lowry methods, respectively (Lowry et al., 1951; Dubois et al., 1956).

Different culture media were prepared by dissolving CSL in demineralized water at different concentrations [5, 10, and 15\% (v/v)]. Subsequently, the $\mathrm{pH}$ was adjusted to 7 using $1 \mathrm{M} \mathrm{NaOH}$ and the media were sterilized at $121^{\circ} \mathrm{C}$ for $15 \mathrm{~min}$. Those media were evaluated for biosurfactant production by B. subtilis \#573 in order to establish the optimum CSL concentration for biosurfactant production. The assays were performed in $500 \mathrm{ml}$ flasks containing $200 \mathrm{ml}$ of each medium. The flasks were inoculated with $2 \mathrm{ml}$ of a pre-culture of B. subtilis \#573 grown in LB medium at $37^{\circ} \mathrm{C}$ and $200 \mathrm{rpm}$ for $24 \mathrm{~h}$. Pre-cultures were prepared by inoculating $10 \mathrm{ml}$ of $\mathrm{LB}$ medium with a single colony taken from an agar plate. The cultures were incubated at the same conditions $\left(37^{\circ} \mathrm{C}\right.$ and $\left.200 \mathrm{rpm}\right)$ until the maximum biosurfactant production was achieved. Samples were taken at different time points during the fermentation to determine biosurfactant production. The samples were centrifuged (4000 rpm, $20 \mathrm{~min}$ ) and the cell-free supernatants were used to measure the ST and to determine the emulsifying activity $\left(\mathrm{E}_{24}\right)$, as described below. Whenever required, the culture broth supernatants were diluted 10 or 100 times with demineralized water and the surface tension $\left(\mathrm{ST}^{-1}, \mathrm{ST}^{-2}\right)$ and emulsifying activities $\left(\mathrm{E}_{24}{ }^{-1}, \mathrm{E}_{24}{ }^{-2}\right)$ were measured.

\section{EFFECT OF METAL MEDIUM SUPPLEMENTATION ON BIOSURFACTANT PRODUCTION}

Once selected the CSL concentration that led to the highest biosurfactant production by B. subtilis \#573, the effect of the addition of different metals (iron, manganese, and magnesium) at different concentrations on biosurfactant production was evaluated in order to try to increase biosurfactant production by this isolate. The metal concentrations used were selected according to previous studies performed by different authors, as shown in Table 1. Control assays were performed using the culture medium without supplements. The cultures were performed at the same conditions described above and the biosurfactant production was evaluated along the fermentation. The cultures were maintained until the maximum biosurfactant production was achieved in each case.

\section{BIOSURFACTANT RECOVERY}

At the end of the fermentation, the cultures were centrifuged (4000 rpm, $20 \mathrm{~min}$ ) to remove the cells. The cell-free supernatants were adjusted to $\mathrm{pH} 2$ with $6 \mathrm{M} \mathrm{HCl}$ and were subsequently incubated overnight at $4^{\circ} \mathrm{C}$ to promote the biosurfactant precipitation. Afterward, the precipitates (crude biosurfactant) were collected by centrifugation $\left(9000 \mathrm{rpm}, 20 \mathrm{~min}, 4^{\circ} \mathrm{C}\right)$. The crude biosurfactant was dissolved in a minimal amount of demineralized water and the $\mathrm{pH}$ was adjusted to 7 using $1 \mathrm{M} \mathrm{NaOH}$. The biosurfactant solutions were freeze-dried and the products obtained were weighed and stored at $-20^{\circ} \mathrm{C}$.

\section{SURFACE-ACTIVITY DETERMINATION}

Surface tension measurements of culture broth supernatants and biosurfactant solutions were performed according to the Ring method described elsewhere (Gudiña et al., 2012). A KRÜSS K6 Tensiometer (KRÜSS GmbH, Germany) equipped with a $1.9 \mathrm{~cm}$ De Noüy platinum ring was used. To increase the accuracy of the ST measurements, an average of triplicates was determined. All the measurements were performed at room temperature $\left(25^{\circ} \mathrm{C}\right)$.

Table 1 | Different salts and concentrations used to study the effect of iron, manganese and magnesium on biosurfactant production by Bacillus subtilis \#573.

\begin{tabular}{|c|c|c|c|}
\hline Compound & Medium & Concentration & Reference \\
\hline \multirow[t]{4}{*}{$\mathrm{FeSO}_{4}$} & A & $0.025 \mathrm{mM}$ & Sen (1997) and Sen and \\
\hline & & & Swaminathan (1997) \\
\hline & $\mathrm{B}$ & $0.3 \mathrm{mM}$ & Wei et al. (2007) \\
\hline & $\mathrm{C}$ & $2.0 \mathrm{mM}$ & Yeh et al. (2005) \\
\hline \multirow[t]{4}{*}{$\mathrm{MnSO}_{4}$} & $\mathrm{D}$ & $0.02 \mathrm{mM}$ & Mnif et al. (2012) \\
\hline & $E$ & $0.2 \mathrm{mM}$ & Wei et al. (2007) \\
\hline & $\mathrm{F}$ & $2.0 \mathrm{mM}$ & Sen (1997) and Sen and \\
\hline & & & Swaminathan (1997) \\
\hline \multirow[t]{5}{*}{$\mathrm{MgSO}_{4}$} & G & $0.8 \mathrm{mM}$ & Sen (1997), Sen and \\
\hline & & & Swaminathan (1997) and \\
\hline & & & Wei et al. (2007) \\
\hline & $\mathrm{H}$ & $2.0 \mathrm{mM}$ & Sousa et al. (2012) \\
\hline & I & $4.0 \mathrm{mM}$ & Akpa etal. (2001) \\
\hline
\end{tabular}




\section{EMULSIFYING ACTIVITY DETERMINATION}

Emulsifying activity was determined by the addition of $2 \mathrm{ml}$ of $n$-hexadecane to the same volume of cell-free supernatants in glass test tubes. The tubes were mixed with a vortex at high speed for $2 \mathrm{~min}$ and then incubated at $25^{\circ} \mathrm{C}$ for $24 \mathrm{~h}$. The emulsification index $\left(\mathrm{E}_{24}\right)$ was calculated as the percentage of the height of the emulsified layer $(\mathrm{mm})$ divided by the total height of the liquid column $(\mathrm{mm})$. All the emulsification indexes were performed in triplicate.

\section{CRITICAL MICELLE CONCENTRATION (cmc)}

Critical micelle concentration is the concentration of an amphiphilic compound in solution at which the formation of micelles is initiated. Different concentrations of the freeze-dried biosurfactant produced by B. subtilis \#573 were prepared in demineralized water, and the ST of each sample was measured at $25^{\circ} \mathrm{C}$ as described above. The $\mathrm{cmc}$ was determined by plotting the ST as a function of the logarithm of biosurfactant concentration, and it was found at the point of intersection between the two lines that best fit through the pre- and post- $\mathrm{cmc}$ data. All the measurements were done in triplicate.

\section{OIL RECOVERY ASSAYS}

The applicability of the biosurfactant produced by B. subtilis \#573 in oil recovery was evaluated using artificially contaminated sand containing $12.5 \%(\mathrm{w} / \mathrm{w})$ of Arabian Light crude oil [kindly provided by GALP (Portugal)]. Samples of $40 \mathrm{~g}$ of sand were mixed with $5 \mathrm{~g}$ of crude oil in $100 \mathrm{ml}$ flasks by shaking, and allowed to age at room temperature for $24 \mathrm{~h}$. Afterward $40 \mathrm{ml}$ of biosurfactant solutions at different concentrations were added to each flask. The flasks were incubated at $90 \mathrm{rpm}$ and $40^{\circ} \mathrm{C}$ for $24 \mathrm{~h}$, and the oil removed was recovered from the surface and transferred to a graduated tube. In order to separate the water recovered together with the crude oil, the tubes were centrifuged ( $9000 \mathrm{rpm}, 20 \mathrm{~min}$, $25^{\circ} \mathrm{C}$ ), and subsequently the volume of crude oil was measured. The amount of oil recovered (grams) was calculated according to its density $(0.837 \mathrm{~g} / \mathrm{ml})$. Control assays were performed using demineralized water at the same conditions. All the experiments were performed in triplicate. Statistically significant differences of the assays performed with the different biosurfactant concentrations tested were evaluated by a one-way ANOVA $(P<0.05)$ applying the Tukey multiple-comparisons; a significant difference was considered if $P<0.05$.

\section{RESULTS \\ EVALUATION OF CSL AS A SUBSTRATE FOR BIOSURFACTANT PRODUCTION}

Bacillus subtilis \#573 was isolated and identified in a previous work as a promising biosurfactant producer (Gudiña et al., 2012). The applicability of the biosurfactant produced by this isolate [identified as a mixture of $\mathrm{C}_{13^{-}}, \mathrm{C}_{14^{-}}$, and $\mathrm{C}_{15^{-}}$-surfactin (Pereira et al., 2013)] in oil recovery (Pereira et al., 2013) and its anti-tumor activity (Duarte et al., 2014) were also demonstrated. In order to optimize biosurfactant production by this isolate and reduce its production costs, CSL was evaluated as a low-cost alternative culture medium. CSL is a by-product of corn wet-milling, where starch is recovered from corn, and it is an important source of nitrogen for several biotechnological processes (Henkel et al., 2012; Gudiña et al., 2015). The CSL used in this work contained $75 \mathrm{~g} / \mathrm{l}$ of carbohydrates and $5 \mathrm{~g} / \mathrm{l}$ of protein.

In order to establish the optimum CSL concentration for biosurfactant production by this isolate, different culture media were prepared by dissolving CSL in demineralized water at different concentrations $[5,10$, and $15 \%(\mathrm{v} / \mathrm{v})]$, and subsequently were evaluated for biosurfactant production. The cultures were incubated at $37^{\circ} \mathrm{C}$ and $200 \mathrm{rpm}$, and biosurfactant production was evaluated along the fermentation by measuring the ST and the emulsifying activity of the cell-free supernatants. The cultures were maintained until the maximum biosurfactant production was achieved in each case. The results obtained are shown in Table 2.

Although with the three media similar ST values were obtained in the cell-free supernatants without dilution, more pronounced differences were observed in the cell-free supernatants 10 and 100 times diluted. With the medium CSL 5\%, the best results regarding biosurfactant production were obtained after $24 \mathrm{~h}$, whereas for the other two media these were obtained after $48 \mathrm{~h}$. From Table 2 it can be seen that the lowest ST values and the highest emulsifying indexes were obtained with the medium CSL $10 \%$, thus indicating a higher biosurfactant production. Taking into account the price of CSL (about $40 € /$ ton), the price of 1 liter of medium CSL $10 \%$ is about $0.004 €$. Therefore, the use of CSL as an alternative culture medium would greatly decrease the production costs of this biosurfactant at a higher production scale.

The cell-free supernatants of cultures performed in CSL 10\% for $48 \mathrm{~h}$ were subjected to acidic precipitation to recover the biosurfactant produced, yielding $1.311 \pm 0.109 \mathrm{~g}$ of biosurfactant per liter. The $\mathrm{cmc}$ calculated for this biosurfactant was $0.16 \mathrm{~g} / \mathrm{l}$. In view of the results obtained, the medium CSL $10 \%$ was selected to perform the following optimization assays.

\section{EFFECT OF METALS ON THE BIOSURFACTANT PRODUCTION}

Iron, manganese, and magnesium are co-factors of enzymes involved in the synthesis of surfactin by B. subtilis. Therefore, the

Table 2 | Surface tension values [ST, $\mathrm{ST}^{-1}$ and $\left.\mathrm{ST}^{-2}(\mathrm{mN} / \mathrm{m})\right]$ and emulsifying indexes $\left[E_{24}, E_{24}^{-1}(\%)\right]$ obtained in cultures performed with $B$. subtilis \#573 grown in media containing CSL at different concentrations $[5,10$, and $15 \%(v / v)]$.

\begin{tabular}{llll}
\hline & CSL 5\% & CSL 10\% & CSL 15\% \\
\hline Time $(\mathrm{h})$ & 24 & 48 & 48 \\
$\mathrm{ST}_{0}(\mathrm{mN} / \mathrm{m})$ & $51.4 \pm 0.4$ & $52.8 \pm 0.3$ & $50.5 \pm 0.4$ \\
$\mathrm{ST}(\mathrm{mN} / \mathrm{m})$ & $32.8 \pm 0.5$ & $30.7 \pm 0.4$ & $31.8 \pm 0.5$ \\
$\mathrm{ST}^{-1}(\mathrm{mN} / \mathrm{m})$ & $50.3 \pm 1.7$ & $34.9 \pm 0.9$ & $40.0 \pm 0.8$ \\
$\mathrm{ST}^{-2}(\mathrm{mN} / \mathrm{m})$ & $72.0 \pm 0.0$ & $59.8 \pm 1.8$ & $67.3 \pm 1.5$ \\
$\mathrm{E}_{24}(\%)$ & $28.0 \pm 3.7$ & $55.0 \pm 2.0$ & $40.3 \pm 1.7$ \\
$\mathrm{E}_{24}{ }^{-1}(\%)$ & 0.0 & $29.0 \pm 6.6$ & 0.0
\end{tabular}

The results presented correspond to the values obtained at the optimum time for each medium. $S T_{0}$ : surface tension of the culture medium. Results represent the average of three independent experiments $\pm S D$. 
Table 3 | Surface tension values $\left[S T, S^{-1}\right.$, and $\left.\mathrm{ST}^{-2}(\mathrm{mN} / \mathrm{m})\right]$, emulsifying indexes $\left[\mathrm{E}_{24}, \mathrm{E}_{24}{ }^{-1}(\%)\right]$ and biosurfactant concentrations obtained in cultures performed with $B$. subtilis \#573 grown in CSL $10 \%$ supplemented with different metals at different concentrations.

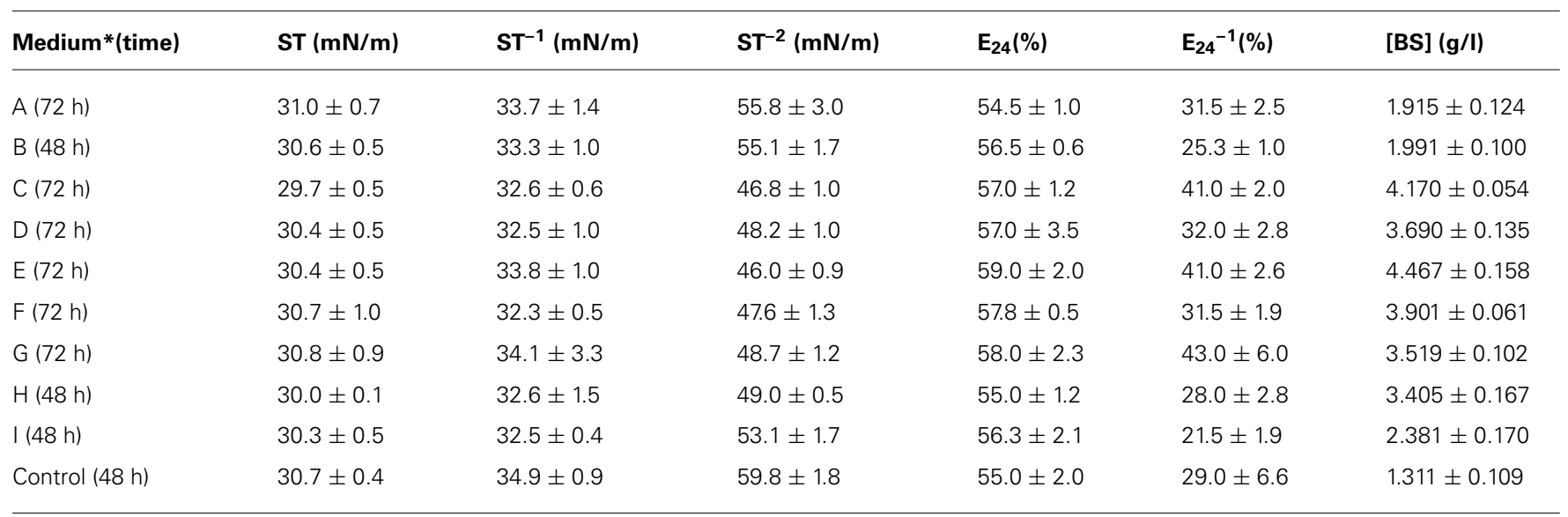

Control: CSL $10 \%$ without supplements.

$S T_{0}: 52.8 \pm 0.3 \mathrm{mN} / \mathrm{m} . S T_{0}{ }^{-1}: 60.3 \pm 0.5 \mathrm{mN} / \mathrm{m}$. ST ${ }_{0}^{-2}: 70.0 \pm 0.8 \mathrm{mN} / \mathrm{m}$. The results presented correspond to the optimum time for each medium. Results represent the average $\pm S D$ of three independent experiments. ${ }^{*}$ The composition of the different culture media is shown in Table 1.

concentration of these elements in the culture medium plays an important role in the biosurfactant production (Sen, 1997; Wei and Chu, 1998, 2002; Wei et al., 2003, 2007). The medium CSL $10 \%$, selected in the previous phase as the best medium for biosurfactant production by $B$. subtilis \#573, was supplemented with $\mathrm{FeSO}_{4}, \mathrm{MnSO}_{4}$, or $\mathrm{MgSO}_{4}$ individually at different concentrations (as shown in Table 1), in order to study their effect on biosurfactant production. The metal concentrations used were selected taking into account previous works from other authors studying biosurfactant production by different $B$. subtilis strains. The medium CSL $10 \%$ without supplements was used as control. As in the previous assays, the cultures were incubated at $37^{\circ} \mathrm{C}$ and $200 \mathrm{rpm}$, and biosurfactant production was evaluated along the time. The cultures were maintained until the maximum biosurfactant production was achieved in each case. The results obtained are gathered in Table 3.

For the experiments conducted with the media B, H, and I, the lowest ST values were obtained at $48 \mathrm{~h}$ of growth, as it was previously observed in the assays performed with the medium CSL $10 \%$. In the other media, the lowest ST values were achieved at $72 \mathrm{~h}$ of growth. Regarding the ST of the cell-free supernatants without dilution, similar values (between 29.7 and $31.0 \mathrm{mN} / \mathrm{m}$ ) were obtained for all the media tested. However, greater differences were observed in the cell-free supernatants that were diluted 10 and 100 times (Table 3).

In the culture media supplemented with $\mathrm{FeSO}_{4}$, the best result was obtained with the highest concentration tested $(2.0 \mathrm{mM}$, medium C). In that case, the $\mathrm{ST}^{-2}$ was reduced up to $46.8 \pm 1.0$ $\mathrm{mN} / \mathrm{m}$ at $72 \mathrm{~h}$, which resulted in a biosurfactant production of $4.170 \pm 0.054 \mathrm{~g} / \mathrm{l}$. Regarding manganese, the best result was obtained with $\mathrm{MnSO}_{4}$ at a concentration $0.2 \mathrm{mM}$ (medium E) at $72 \mathrm{~h}$. The $\mathrm{ST}^{-2}$ was reduced up to $46.0 \pm 0.9 \mathrm{mN} / \mathrm{m}$, and the amount of biosurfactant produced was $4.467 \pm 0.158 \mathrm{~g} / \mathrm{l}$. In the media supplemented with magnesium, similar results were obtained with $\mathrm{MgSO}_{4} 0.8$ and $2.0 \mathrm{mM}$ (media $\mathrm{G}$ and $\mathrm{H}$ ). The $\mathrm{ST}^{-2}$ was reduced up to $48.7-49.0 \mathrm{mN} / \mathrm{m}$, and the amount of biosurfactant produced ranged between 3.4 and $3.5 \mathrm{~g} / \mathrm{l}$. In all the cases a direct relationship was found between the $\mathrm{ST}^{-2}$ values and the amount of biosurfactant produced (Table 3).

Regarding the emulsifying indexes, similar values (54.5-59.0\%) were obtained with all the media assayed (Table 3). Emulsifying indexes higher than $50 \%$ entail that the hydrocarbon phase is completely emulsified. More pronounced differences were observed for the $\mathrm{E}_{24}{ }^{-1}$ values. The highest $\mathrm{E}_{24}{ }^{-1}$ values were obtained with the media C, E, and G, which is in agreement with the amounts of biosurfactant produced in each medium.

As it can be seen from the results obtained, the supplementation of the medium CSL 10\% with the different metals resulted in an increase in biosurfactant production in all the cases when compared with the medium without supplements, although for each metal, that effect was dependent on the concentration used.

It has been reported that the combination of different metals can result in a positive interaction on surfactin production as compared with their individual effect (Sen, 1997; Makkar and Cameotra, 2002). Taking into account the results obtained with the medium CSL 10\% supplemented with the different metals

Table 4 | Combinations of metal salts assayed for studying its effect on the biosurfactant production by $B$. subtilis \#573.

\begin{tabular}{lll}
\hline Medium & Compound & Concentration \\
\hline $\mathrm{J}$ & $\mathrm{FeSO}_{4}$ & $2.0 \mathrm{mM}$ \\
$\mathrm{MgSO}_{4}$ & $0.8 \mathrm{mM}$ \\
\hline $\mathrm{K}$ & $\mathrm{FeSO}_{4}$ & $2.0 \mathrm{mM}$ \\
& $\mathrm{MnSO}_{4}$ & $0.2 \mathrm{mM}$ \\
\hline $\mathrm{L}$ & $\mathrm{MgSO}_{4}$ & $0.8 \mathrm{mM}$ \\
& $\mathrm{MnSO}_{4}$ & $0.2 \mathrm{mM}$ \\
\hline $\mathrm{M}$ & $\mathrm{FeSO}_{4}$ & $2.0 \mathrm{mM}$ \\
& $\mathrm{MgSO}_{4}$ & $0.8 \mathrm{mM}$ \\
& $\mathrm{MnSO}_{4}$ & $0.2 \mathrm{mM}$
\end{tabular}


individually, this medium was supplemented with different metal combinations, according with the concentrations that led to the best results in the individual assays for each compound, namely $\mathrm{FeSO}_{4} 2.0 \mathrm{mM}, \mathrm{MnSO}_{4} 0.2 \mathrm{mM}$, and $\mathrm{MgSO}_{4} 0.8 \mathrm{mM}$. The different combinations assayed are summarized in Table 4. As in the previous assays, the cultures were incubated at $37^{\circ} \mathrm{C}$ and $200 \mathrm{rpm}$, and biosurfactant production was evaluated along the time. The medium CSL 10\% without supplements was used as control. The cultures were maintained until the maximum biosurfactant production was achieved in each case. The results obtained are gathered in Table 5 .

Regarding the combinations iron-magnesium (medium J) and iron-manganese (medium $\mathrm{K}$ ), the best results regarding ST reduction and biosurfactant production were obtained at $24 \mathrm{~h}$ of growth. However, the amount of biosurfactant produced $(2.704 \pm 0.132$ and $3.933 \pm 0.205 \mathrm{~g} / \mathrm{l}$, respectively) was lower than the obtained when those metals were added individually, which suggests a negative interaction on the biosurfactant production. Regarding the combination magnesium-manganese (medium L), the best results were obtained after $48 \mathrm{~h}$. In this case, the amount of biosurfactant produced $(4.224 \pm 0.157 \mathrm{~g} / \mathrm{l})$ was slightly lower when compared with the obtained with the optimum concentration of manganese, but better than the obtained with the optimum concentration of magnesium. Finally, a combination of the three metals was tested (medium M). The best results were obtained at $72 \mathrm{~h}$, and the amount of biosurfactant produced $(4.829 \pm 0.193 \mathrm{~g} / \mathrm{l})$ was higher than the obtained when the different metals were added individually.

\section{OIL RECOVERY ASSAYS}

The oil recovery assays were performed using the freeze-dried biosurfactant produced by B. subtilis \#573 in the medium CSL 10\%, dissolved in demineralized water at different concentrations. The results obtained are shown in Table 6.

As it can be seen from Table 6, similar oil recoveries were obtained with the biosurfactant at a concentration of 2.5 and $5.0 \mathrm{~g} / \mathrm{l}$ [the differences were not statistically significant $(P>0.05)$ ], which suggests that the use of higher biosurfactant concentrations would not increase the oil recovery.

\section{DISCUSSION}

Biosurfactant production by B. subtilis isolates using low-cost substrates was studied by several authors. B. subtilis B20 and B30 produced between 0.3 and $2.3 \mathrm{~g} / \mathrm{l}$ of biosurfactant using a mineral medium supplemented with date molasses as carbon source (Al-Bahry et al., 2013; Al-Wahaibi et al., 2014). Abdel-Mawgoud et al. (2008) reported a biosurfactant production of $1.12 \mathrm{~g} / \mathrm{l}$ by B. subtilis BS5 using a mineral medium containing sugarcane molasses. B. subtilis LAMI005 produced 0.3 and $0.44 \mathrm{~g} / \mathrm{l}$ of biosurfactant growing in media containing cashew apple juice (Oliveira et al., 2013) and raw glycerol derived from biodiesel production (Sousa et al., 2012), respectively. However, in these cases, other nutrients (e.g., carbon or nitrogen sources, salts) were added to the media, thus increasing their prices. On the contrary, in the present work, the only substrate used to prepare the culture media was CSL. Likewise, other authors reported biosurfactant production by different $B$. subtilis isolates using culture media containing exclusively agro-industrial by-products (e.g., cassava wastewater, sugarcane molasses, or rehydrated whey powder), with productivities between 0.3 and $3.0 \mathrm{~g} / \mathrm{l}$ (Nitschke and Pastore, 2006; Joshi et al., 2008; Cagri-Mehmetoglu et al., 2012). However, to the best of our knowledge, this is the first report describing biosurfactant production by $B$. subtilis using CSL as culture medium. The amount of biosurfactant produced (about $1.3 \mathrm{~g} / \mathrm{l}$ ) was close to the values reported by other authors using different substrates.

It has been reported that the addition of iron, magnesium or manganese to the culture medium increased biosurfactant production by B. subtilis isolates (Thimon et al., 1992; Wei and Chu, 1998, 2002; Makkar and Cameotra, 2002; Al-Ajlani et al., 2007). $\mathrm{Mn}^{2+}$ at a concentration $0.01 \mathrm{mM}$ increased biosurfactant production by B. subtilis ATCC 21332 from 0.33 to $2.6 \mathrm{~g} / \mathrm{l}$ (Wei and Chu, 2002). Al-Ajlani et al. (2007) reported an increase in biosurfactant production by $B$. subtilis MZ-7 from 0.22 to $0.3 \mathrm{~g} / \mathrm{l}$ by supplementing the culture medium with $\mathrm{Fe}^{2+}$ at a concentration $4.0 \mathrm{mM}$; and similar results were obtained by Thimon et al. (1992). Makkar and Cameotra (2002) increased biosurfactant production by B. subtilis MTCC 2423 growing in a mineral medium from 0.342 to $0.814 \mathrm{~g} / \mathrm{l}$ by the addition of $\mathrm{FeSO}_{4}(0.719 \mathrm{mM})$, and to $0.792 \mathrm{~g} / \mathrm{l}$ by the addition of $\mathrm{MgSO}_{4}(2.43 \mathrm{mM})$. However, in some cases, higher concentrations of those metals inhibited biosurfactant production (Makkar and Cameotra, 2002). In our case, the amount of biosurfactant produced by B. subtilis \#573 in the medium CSL $10 \%$ was increased up to $3.2,3.4$, and 2.7 times due to the addition of iron, manganese, and magnesium, respectively, to the culture medium.

Table 5 | Surface tension values $\left[S T, S^{-1}\right.$, and $\left.\mathrm{ST}^{-2}(\mathrm{mN} / \mathrm{m})\right]$, emulsifying indexes $\left[\mathrm{E}_{24}, \mathrm{E}_{24}{ }^{-1}(\%)\right.$ ] and biosurfactant concentrations obtained in cultures performed with $B$. subtilis \#573 grown in CSL $10 \%$ supplemented with different combinations of metals.

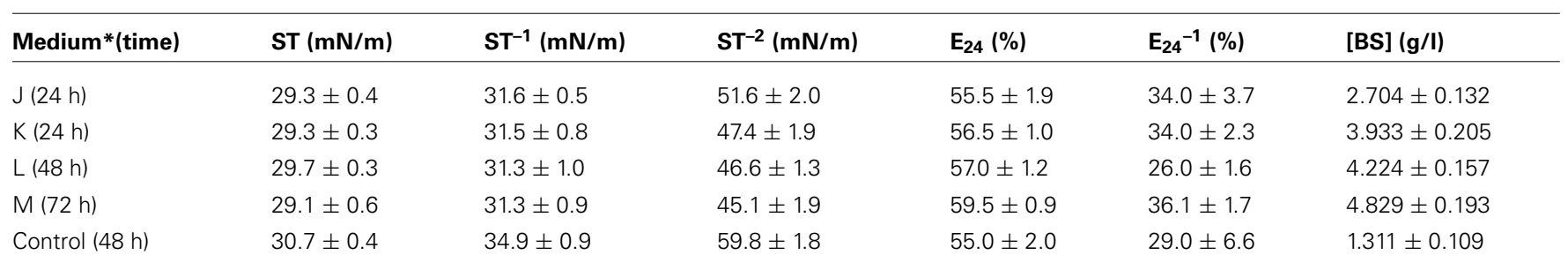

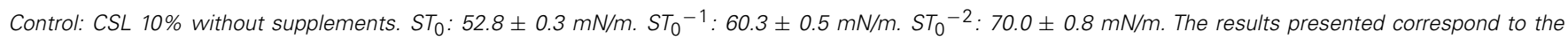
optimum time for each medium. Results represent the average $\pm S D$ of three independent experiments.

*The composition of the different culture media is shown in Table 4 
Table 6 | Percentages of oil recovered with the biosurfactant produced by $B$. subtilis \#573 in the medium CSL $10 \%$ at different concentrations.

\begin{tabular}{ll}
\hline [BS] $\mathbf{g} / \mathbf{l}$ & Oil recovered $(\%)$ \\
\hline 5.0 & $25.1 \pm 1.7$ \\
2.5 & $26.3 \pm 0.0$ \\
1.0 & $15.0 \pm 0.8$ \\
Control & $0.0 \pm 0.0$ \\
\hline
\end{tabular}

Results represent the average $\pm S D$ of three independent experiments.

Sen (1997) reported a strong and positive interaction between iron and manganese in the biosynthesis of surfactin by B. subtilis. Wei et al. (2007) increased biosurfactant production by B. subtilis ATCC 21332 from 1.74 to $3.34 \mathrm{~g} / \mathrm{l}$ through the optimization of the trace elements composition $\left(\mathrm{Mg}^{2+}, \mathrm{K}^{+}, \mathrm{Mn}^{2+}, \mathrm{Fe}^{2+}\right.$, and $\left.\mathrm{Ca}^{2+}\right)$. Makkar and Cameotra (2002) also reported an increase on biosurfactant production by B. subtilis MTCC 2423 from 0.342 to $1.230 \mathrm{~g} / \mathrm{l}$ when the culture medium was supplemented with the optimum concentrations of magnesium, iron, and calcium simultaneously, and this effect was higher than the obtained when the different metals were added individually. In our case, a combination of $\mathrm{FeSO}_{4} 2.0 \mathrm{mM}, \mathrm{MgSO}_{4} 0.8 \mathrm{mM}$, and $\mathrm{MnSO}_{4} 0.2 \mathrm{mM}$ increased biosurfactant production 3.6 times as compared with the medium without supplements.

Regarding the oil recovery assays, in a previous work, the biosurfactant produced by this isolate in a mineral medium (containing sucrose as the carbon source and ammonium nitrate as the nitrogen source) recovered $18.8 \pm 1.1 \%$ of oil at a concentration of $1 \mathrm{~g} / \mathrm{l}$ (Pereira etal., 2013). That value is higher than the obtained in the current work $(15.0 \pm 0.8 \%)$ at the same conditions. However, the $\mathrm{cmc}$ calculated for the biosurfactant produced in the mineral medium by this isolate was $0.03 \mathrm{~g} / \mathrm{l}$ (Pereira et al., 2013), whereas for the biosurfactant produced in CSL $10 \%$ it was $0.16 \mathrm{~g} / \mathrm{l}$. This can explain the differences observed in the percentages of oil recovered in both cases. Nevertheless, the results obtained in this work are still better comparing with the oil recoveries obtained with the chemical surfactants Enordet and Petrostep at the same concentrations and conditions (9-12\%; Pereira et al., 2013), thus suggesting that this biosurfactant can be useful for application in microbial enhanced oil recovery or bioremediation.

\section{CONCLUSION}

Biosurfactant production by $B$. subtilis \#573 was evaluated using CSL as an alternative low-cost culture medium. The use of such substrate led to a surfactin production of about $1.3 \mathrm{~g} / \mathrm{l}$, which is in good agreement with the values reported so far in the literature. To our knowledge this is the first report on the use of CSL for the production of surfactin. Besides, if an industrial scale is envisaged, the use of CSL as culture medium would have a huge impact in the surfactin production costs. Additionally, the amount of biosurfactants produced using this alternative medium was increased about 3 to 4 times when metal salts were used as supplements, thus representing an even higher impact on the production costs. It is important to mention that the surfactin produced from these alternative media retained all its previously reported properties, including its great potential for microbial enhanced oil recovery or bioremediation applications.

\section{AUTHOR CONTRIBUTIONS}

All authors contributed to the design of the work. Eduardo J. Gudiña, Elisabete C. Fernandes and Ana I. Rodrigues performed the experimental work and wrote part of the manuscript. José A. Teixeira and Lígia R. Rodrigues participated in the design of the study and drafted the manuscript. All authors read and approved the final manuscript.

\section{ACKNOWLEDGMENTS}

The authors acknowledge the financial support from the Strategic Project PEst-OE/EQB/LA0023/2013 and project ref. RECI/BBB-EBI/0179/2012 (project number FCOMP-01-0124FEDER-027462) funded by Fundação para a Ciência e a Tecnologia, and from AdI (Agência de Inovação, S. A.), through the project BIOCLEAN - "Development of biosurfactant-based products for surfaces cleaning and desinfection in the food industry" (QREN Ref. 30215).

\section{REFERENCES}

Abdel-Mawgoud, A. M., Aboulwafa, M. M., and Hassouna, N. A. H. (2008). Optimization of surfactin production by Bacillus subtilis isolate BS5. Appl. Biochem. Biotechnol. 150, 305-325. doi: 10.1007/s12010-008-8155-x

Akpa, E., Jacques, P., Wathelet, B., Paquot, M., Fuchs, R., Budzikiewicz, H., et al. (2001). Influence of culture conditions on lipopeptide production by Bacillus subtilis. Appl. Biochem. Biotechnol. 91-93, 551-562. doi: 10.1385/ABAB:91-93:19:551

Al-Ajlani, M. M., Sheikh, M. A., Ahmad, Z., and Hasnain, S. (2007). Production of surfactin from Bacillus subtilis MZ-7 grown on pharmamedia commercial medium. Microb. Cell Fact. 6, 17. doi: 10.1186/1475-2859-6-17

Al-Bahry, S. N., Al-Wahaibi, Y. M., Elshafie, A. E., Al-Bemani, A. S., Joshi, S. J., Al-Makhmari, H. S., et al. (2013). Biosurfactant production by Bacillus subtilis B20 using date molasses and its possible application in enhanced oil recovery. Int. Biodeterior. Biodegradation 81, 141-146. doi: 10.1016/j.ibiod.2012. 01.006

Al-Wahaibi, Y., Joshi, S., Al-Bahry, S., Elshafie, A., Al-Bemani, A., and Shibulal, B. (2014). Biosurfactant production by Bacillus subtilis B30 and its application in enhancing oil recovery. Colloids Surf. B Biointerfaces 114, 324-333. doi: 10.1016/j.colsurfb.2013.09.022

Cagri-Mehmetoglu, A., Kusakli, S., and van de Venter, M. (2012). Production of polysaccharide and surfactin by Bacillus subtilis ATCC 6633 using rehydrated whey powder as the fermentation medium. J. Dairy Sci. 95, 3643-3649. doi: $10.3168 /$ jds.2012-5385

Das, K., and Mukherjee, A. K. (2007). Comparison of lipopeptide biosurfactants production by Bacillus subtilis strains in submerged and solid state fermentation systems using a cheap carbon source: some industrial applications of biosurfactants. Process Biochem. 42, 1191-1199. doi: 10.1016/j.procbio.2007. 05.011

Duarte, C., Gudiña, E. J., Lima, C. F., and Rodrigues, L. R. (2014). Effects of biosurfactants on the viability and proliferation of human breast cancer cells. AMB Express 4, 40. doi: 10.1186/s13568-014-0040-0

Dubois, M., Gilles, K. A., Hamilton, J. K., Rebers, P. A., and Smith, F. (1956). Colorimetric method for determination of sugars and related substances. Anal. Chem. 28, 350-356. doi: 10.1021/ac60111a017

Geys, R., Soetaert, W., and Van Bogaert, I. (2014). Biotechnological opportunities in biosurfactant production. Curr. Opin. Biotechnol. 30, 66-72. doi: 10.1016/j.copbio.2014.06.002

Gudiña, E. J., Pereira, J. F. B., Rodrigues, L. R., Coutinho, J. A. P., and Teixeira, J. A. (2012). Isolation and study of microorganisms from oil samples for application in microbial enhanced oil recovery. Int. Biodeterior. Biodegradation 68, 56-64. doi: 10.1016/j.ibiod.2012.01.001 
Gudiña, E. J., Rangarajan, V., Sen, R., and Rodrigues, L. R. (2013). Potential therapeutic applications of biosurfactants. Trends Pharmacol. Sci. 34, 667-675. doi: 10.1016/j.tips.2013.10.002

Gudiña, E. J., Rodrigues, A. I., Alves, E., Domingues, M. R., Teixeira, J. A., and Rodrigues, L. R. (2015). Bioconversion of agro-industrial by-products in rhamnolipids toward applications in enhanced oil recovery and bioremediation. Bioresour. Technol. 177, 87-93. doi: 10.1016/j.biortech.2014.11.069

Henkel, M., Müller, M. M., Kügler, J. H., Lovaglio, R. B., Contiero, J., Syldatk, C. et al. (2012). Rhamnolipids as biosurfactants from renewable resources: concepts for next-generation rhamnolipid production. Process Biochem. 47, 1207-1219. doi: 10.1016/j.procbio.2012.04.018

Joshi, S., Bharucha, C., Jha, S., Yadav, S., Nerurkar, A., and Desai, A. J. (2008). Biosurfactant production using molasses and whey under thermophilic conditions. Bioresour. Technol. 99, 195-199. doi: 10.1016/j.biortech.2006.12.010

Lowry, O. H., Rosebrough, N. J., Farr, A. L., and Randall, R. J. (1951). Protein measurement with the Folin phenol reagent. J. Biol. Chem. 193, 265-275.

Makkar, R. S., and Cameotra, S. S. (2002). Effects of various nutritional supplements on biosurfactant production by a strain of Bacillus subtilis at $45^{\circ} \mathrm{C}$. J. Surfactants Deterg. 5, 11-17. doi: 10.1007/s11743-002-0199-8

Mnif, I., Chaabouni-Ellouze, S., and Ghribi, D. (2012). Optimization of the nutritional parameters for enhanced production of Bacillus subtilis SPB1 biosurfactant in submerged culture using response surface methodology. Biotechnol. Res. Int. 2012, 1-8. doi: 10.1155/2012/795430

Nitschke, M., and Pastore, G. M. (2006). Production and properties of a surfactant obtained from Bacillus subtilis grown on cassava wastewater. Bioresour. Technol. 97, 336-341. doi: 10.1016/j.biortech.2005.02.044

Oliveira, D. W. F., Sousa, J. R., França, I. W. L., Felix, A. K. N., Martins, J. J. L., and Gonçalves, L. R. B. (2013). Kinetic study of biosurfactant production by Bacillus subtilis LAMI005 grown in clarified cashew apple juice. Colloids Surf. B Biointerfaces 101, 34-43. doi: 10.1016/j.colsurfb.2012.06.011

Pereira, J. F. B., Gudiña, E. J., Costa, R., Vitorino, R., Teixeira, J. A., Coutinho, J. A. P., et al. (2013). Optimization and characterization of biosurfactant production by Bacillus subtilis isolates towards microbial enhanced oil recovery applications. Fuel 111, 259-268. doi: 10.1016/j.fuel.2013.04.040

Rebello, S., Asok, A. K., Mundayoor, S., and Jisha, M. S. (2014). Surfactants: toxicity, remediation and green surfactants. Environ. Chem. Lett. 12, 275-287. doi: 10.1007/s10311-014-0466-2

Sen, R. (1997). Response surface optimization of the critical media components for the production of surfactin. J. Chem. Technol. Biotechnol. 68, 263-270. doi: 10.1002/(SICI)1097-4660(199703)68:3<263::AID-JCTB631>3.0.CO;2-8

Sen, R., and Swaminathan, T. (1997). Application of response-surface methodology to evaluate the optimum environmental conditions for the enhanced production of surfactin. Appl. Microbiol. Biotechnol. 47, 358-363. doi: $10.1007 /$ s002530050940
Sousa, M., Melo, V. M. M., Rodrigues, S., Santana, H. B., and Gonçalves, L. R. B (2012). Screening of biosurfactant-producing Bacillus strains using glycerol from the biodiesel synthesis as main carbon source. Bioprocess Biosyst. Eng. 35, 897-906. doi: 10.1007/s00449-011-0674-0

Thimon, L., Peypoux, F., and Michel, G. (1992). Interactions of surfactin, a biosurfactant from Bacillus subtilis, with inorganic cations. Biotechnol. Lett. 14, 713-718. doi: 10.1007/BF01021648

Vaz, D. A., Gudiña, E. J., Alameda, E. J., Teixeira, J. A., and Rodrigues, L. R. (2012). Performance of a biosurfactant produced by a Bacillus subtilis strain isolated from crude oil samples as compared to commercial chemical surfactants. Colloids Surf. B Biointerfaces 89, 167-174. doi: 10.1016/j.colsurfb.2011.09.009

Wei, Y. H., and Chu, I. M. (1998). Enhancement of surfactin production in ironenriched media by Bacillus subtilis ATCC21332. Enzyme Microb. Technol. 22, 724-728. doi: 10.1016/S0141-0229(98)00016-7

Wei, Y. H., and Chu, I. M. (2002). Mn2+ improves surfactin production by Bacillus subtilis. Biotechnol. Lett. 24, 479-482. doi: 10.1023/A:1014534021276

Wei, Y. H., Lai, C. C., and Chang, J. S. (2007). Using Taguchi experimental design methods to optimize trace element composition for enhanced surfactin production by Bacillus subtilis ATCC21332. Process Biochem. 42, 40-45. doi: 10.1016/j.procbio.2006.07.025

Wei, Y. H., Wang, L. F., Chang, J. S., and Kung, S. S. (2003). Identification of induced acidification in iron-enriched cultures of Bacillus subtilis during biosurfactant fermentation. J. Biosci. Bioeng. 96, 174-178. doi: 10.1016/S1389-1723(03)90121-6

Yeh, M. S., Wei, Y. H., and Chang, J. S. (2005). Enhanced production of surfactin from Bacillus subtilis by addition of solid carriers. Biotechnol. Prog. 21, 1329-1334. doi: 10.1021/bp050040c

Conflict of Interest Statement: The authors declare that the research was conducted in the absence of any commercial or financial relationships that could be construed as a potential conflict of interest.

Received: 09 November 2014; accepted: 17 January 2015; published online: 06 February 2015.

Citation: Gudiña EJ, Fernandes EC, Rodrigues AI, Teixeira JA and Rodrigues LR (2015) Biosurfactant production by Bacillus subtilis using corn steep liquor as culture medium. Front. Microbiol. 6:59. doi: 10.3389/fmicb.2015.00059

This article was submitted to Microbiotechnology, Ecotoxicology and Bioremediation, a section of journal Frontiers in Microbiology.

Copyright (c) 2015 Gudiña, Fernandes, Rodrigues, Teixeira and Rodrigues. This is an open-access article distributed under the terms of the Creative Commons Attribution License (CC BY). The use, distribution or reproduction in other forums is permitted, provided the original author(s) or licensor are credited and that the original publication in this journal is cited, in accordance with accepted academic practice. No use, distribution or reproduction is permitted which does not comply with these terms. 